\title{
Introduction to the Memorial Issue Dedicated to Roger G. Bates (1912-2007)
}

\author{
Arthur K. Covington
}

Published online: 28 August 2009

(C) Springer Science+Business Media, LLC 2009

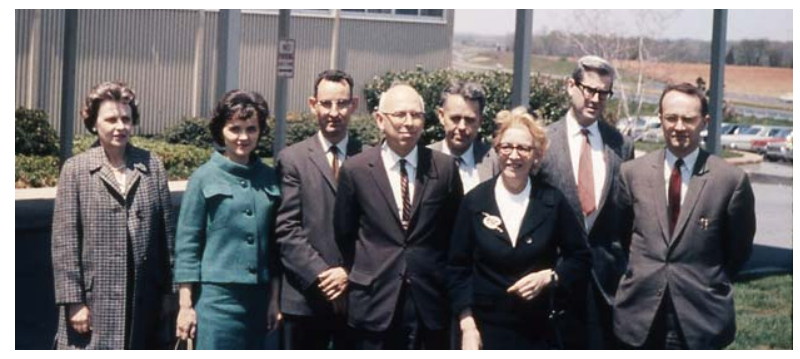

Roger Bates' Section, NBS Gaithersberg, May 1966

Left to right: Hannah Hetzer, Maya Paabo, Tom Hoover, Roger Bates, Cyrus Malmberg, Section Secretary, Vince Bower, Arthur Covington.

As most readers of this Journal will already know from the obituary published last year [1], Roger Bates died in August 2007 in Gainesville, Florida at the age of 95. He worked at the National Bureau of Standards (now NIST) from 1939 until 1969 when he became a professor of chemistry at the University of Florida, Gainesville in the department headed by Herb Laitinen. Roger is widely recognized for his pioneering work which culminated in the operational definition of $\mathrm{pH}$ and for the establishment of the IUPAC Standard $\mathrm{pH}$ Scale; a scale fixed by standards, whose $\mathrm{pH}$ values are consistent with solution thermodynamics coupled with a conventional definition of single-ion activity (the Bates-Guggenheim Convention). $\mathrm{He}$ is perhaps best known for his graduate level text on $\mathrm{pH}$ determination, "Determination of $\mathrm{pH}$, Theory and Practice". Roger had a long-term collaboration with R.A. Robinson, who spent periods in Roger's laboratory after he had retired from the University of Malaya, that

A.K. Covington $(\bowtie)$

University of Newcastle, Newcastle upon Tyne, UK

e-mail: A.K.Covington@newcastle.ac.uk 
amongst other things led to the proposal of a convention for single-ion activities based on Robinson's theories of ion hydration, and a conventional scale of ion activities for the standardization of ion-selective electrodes.

With such a long interval between Roger's second retirement in 1979 and the present, it has not been easy to solicit material for this Memorial Issue as so many of his former coworkers have themselves already retired with nothing in their 'bottom drawers' remaining unpublished (unlike this Guest Editor). Accordingly, most contributors to this issue are from a later generation, who came into contact with Roger from his international activities with IUPAC, and from meeting him at international conferences. Here then, is a collection of papers; our tribute to a great, much revered scientist and person.

\section{References}

1. Covington, A.K.: Obituary: A tribute to Roger G. Bates (1912-2007). J. Solution Chem. 37, 713-714 (2008) 